\title{
Experimental fragmentation of pipe bombs with varying case thickness
}

\section{ARTICLE INFO}

Article history:

Received

Received in revised form

Accepted

Available online

Keywords:

Pipe Bombs

forensic science

fragmentation

\begin{abstract}
Among all the improvised explosive devices (IEDs) known, pipe bombs are one of the most popular devices used by terrorists. They are simple to use, easy to construct and materials are readily available. For this IED, fragmentation is the primary injury mechanism, which makes them a desirable weapon for terrorists aiming to inflict maximum human casualties. Although the investigation of fragmentation pattern is not novel, there is limited data available on pipe bombs performance in the open literature. Therefore, this research is looking at validating results in current literature, which showed limited repetition and weak experimental design so far; by trial with six pipe bombs with two different thickness (3 of each). The pipe bombs consisted of mild steel casing and aluminised ammonium nitrate as the explosive filler. Fragments were collected, with an average recovery of $72 \%$, and measured regarding mass and velocity. The experiment results show a correlation between the pipe thickness and both the size and velocity of fragments.
\end{abstract}

\section{Introduction}

Typically pipe bombs are improvised explosive devices (IEDs) which consist of a container, either plastic or metallic, usually filled with low explosive and threaded with two end caps to provide enough confinement for a detonation [1-5]. Low explosives are known for having a velocity of explosion lower than the speed of sound, subsonic reactions and not exhibiting a detonation wave. However, when confined within an adequate container (i.e. a pipe bomb) and initiated by a detonator (e.g. a blasting cap), they can display a physical behaviour similar to high explosives (HE) [2]. This mechanism is commonly referred to as deflagration to detonation transition [1].

Following a chemical explosion, there are four physical effects: blast, ancillary, thermal, and fragmentation. The blast effect is a result of the rapid expansion of gaseous detonation products, which creates a blast wave that travels at very high speed, usually starting with a Mach number of about three and then decaying monotonically with to ambient speed of sound $(340 \mathrm{~m} / \mathrm{s})$ over large distances, and that increases the ambient pressure to peak incident pressures [6]. The ancillary effects, also known as secondary blast pressure effects, relate to the interaction of the blast wave with water, soil and other objects. This leads to reflection and refraction of the blast wave which in turn can cause blast focusing and higher than expected damage [2]. The thermal effect is a direct consequence of the heat produced by a chemical reaction. As the temperatures can reach or even exceed $7,000 \stackrel{\circ}{\circ}$ $\left(3871^{\circ} \mathrm{C}\right)$ during an explosion and depending on how close victims and/or materials were to the explosion, these effects may occur in the form of severe burning or charred and deformed materials [2]. The fourth outcome, the fragmentation effect, is the main injury mechanism of pipe bombs [5] and can be a result of either the rupture of the casing (primary fragments) or the materials accelerated by the blast waves (secondary fragments) $[5,7]$. For the purpose of this study, secondary fragments are not considered.

\subsection{Post-blast investigation}

In post-blast scenes, from the fragmentation pattern found from a detonated explosive device, a forensic investigator, with the help of a forensic laboratory, have to be able to formulate a hypothesis regarding the explosive filler and the initiation system used in the bombing. This analysis is part of an investigative process that begins with an initial response when various first responders (emergency services) arrive at the scene. After the first responder's initial assessment, a forensic team is called upon to conduct a more in-depth evaluation of the scene with aims to determine whether it was an accidental or criminal event and document its conclusion. After recording the scene through various forms, evidence is identified, collected and sent to the lab. After conducting a final survey to make sure all the investigative steps have been done, the team release the scene to a competent authority and the field investigation starts. The field investigation is where questions such as what the explosive filler and the bomb material were, from where it came and to whom the bomb belonged to, are made 
by the forensic team. To find those answers, an extensive laboratory examination followed of further investigation is conducted [2].

According to the Global Terrorism Database (GTD), created by the University of Maryland, between 1970 to 2016 there have been 2,456 reported incidents of pipe bomb usage worldwide [8]. While this data is important to note, much of the data is extracted from worldwide news outlets, thus the data quality may be limited. An alternative database is the Explosives Incident Report (EIR) published annually by the United States Bomb Data Centre (USBDC), which is the result of several forensic investigations on terrorist and domestic attacks involving explosives in American soil [9-12].

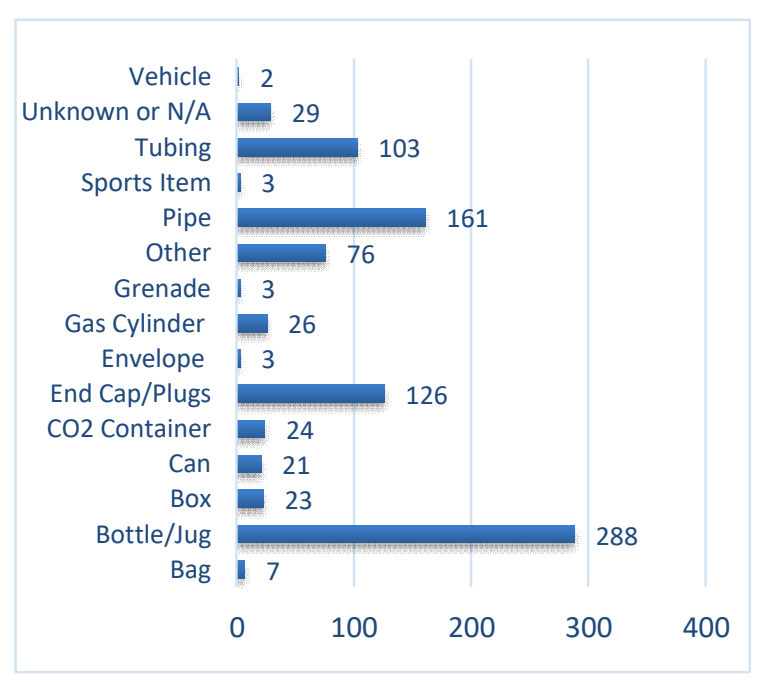

Figure 1 - Number of explosives incidents reported for each container type in EIR between 2014 and 2017 by USBDC. Unknown or N/A is applied when either a container was unknown at the time of entry or the device found had no container.

According to EIR (Fig. 1), between 2014 and 2017, among all the containers used in attacks in America, pipe bombs took the second place with 161 events out of 895 incidents. As these devices are easy to use, simple to build and their materials are easy to obtain, they have become quite popular among terrorist groups over the years. This ease of acquisition is represented by a percentage increase in the use of pipe bombs in 2014 (9\% of 137 events), 2015 (20\% of 254 events) and 2016 (25\% of 240 events) [9-11]. Even though those numbers declined in 2017 (14\% of 264 events) [12], in each of these events, fragmentation was the primary cause of injury and thus remaining an important area of study [5]. To date, fragmentation and its effects have been extensively studied.

\subsection{Previous Work}

Fragmentation is a process that happens when a material undergoes multiple fractures when subjected to stress. The stress can be due to static forces, such as grinding and crushing, or dynamic loadings, such as the impact of a projectile into a target or the expansion of gaseous products from a detonation [13]. Extensive work has been done on the formation of fragmentation of warheads, which are usually build from a suitable steel casing and filled with HE [13-19].

When a detonation occurs, the expansion of gaseous products creates a shockwave that travels at very high velocities. The gases and the shockwave drive and compress the shell wall, causing elastic strain. Once the stress actuating at the inner surface of the casing overcomes the yield strength, the material undergoes through a plastic deformation expanding the area under stress towards the outer face of the wall. The shell remains increasing its diameter until the hoop stress reaches a level for which the casing fails and break $[20,21]$.

The fracture process happens through crack formation and propagation and can undergo through two modes: ductile or brittle fracture. The ductile fracture is represented by an extensive plastic deformation in the vicinity of an advancing crack, which means that the crack resists any further extension unless more stress is applied. Whereas, the brittle fracture is recognized when cracks can spread very quickly, with very little plastic deformation, and once the crack formation process started, it will continue without requiring the increase of stress applied [22].

Due to shear and radial fractures, the cracks begin outside of the shell and move toward the interior. On the other hand, the inherent materials flaws, such as voids, inclusions and weak grain boundaries, also generates cracks that moves from the interior towards the exterior at a $45^{\circ}$ angle. When both kinds of cracks meet, fragments are produced and the gases from detonation keep accelerating those fragments though the opens until they reach their maximum values [20]. Depending on the toughness, density and grain size of the casing material, the warhead breaks into fragments with different shapes and sizes.

Over the years, several theories investigating the fragmentation process were conceived, however, two notable mathematical models are the Gurney [23] and Mott [19] models. In 1943, Gurney developed a mathematical model used to predict the rule of dispersion of fragments driven by $\mathrm{HE}$ in a variety of casing geometries [23]. In his approach, when the warhead is on-axis-initiated, the fragments velocity of a cylindrical bomb with no end caps, behave as follow:

$$
v=\frac{\sqrt{2 E}}{\sqrt{\frac{M}{C}+\frac{1}{2}}}
$$

where $v$ - fragment velocity, $\sqrt{2 E}$ - Gurney constant (depends only on the explosive), $\mathrm{M}$ - casing mass and $\mathrm{C}-$ explosive mass.

However, in the case of pipe bomb events, HE are not commonly used, thus the suitability of this model to predict fragment velocities from these events may be limited.

In 1947, Mott [19] developed a theory for predicting the length of the average fragment of cylindrical "ring-bombs" caused by radial fracture. In this theory, two assumptions were made: the casing wall consists of a series of axisymmetric circular rings, with the same inner and outer diameter, stacked one above the other with a thin steel wall and once the fracture begins, it happens so fast that it can be considered instantaneous relative to the rate of strain of the metal. As an outcome of their work, they derived an equation determining that the mean fragment size depends on the radius and velocity of the ring at the moment of rupture and other mechanical properties of the casing. 


$$
x \propto \sigma_{F} \frac{r}{v} \sqrt{\frac{1+\varepsilon_{F}}{\rho \sigma_{2}}}
$$

Where $x$ - average fragment length $[m], \sigma_{F}-$ true fracture stress [MPa], $\varepsilon_{F}-$ fracture strain based on reduction of area, $\rho-$ density of casing material $\left[\mathrm{kg} \cdot \mathrm{m}^{-3}\right], \sigma_{2}-$ coefficient of stress strain curve for large strains [MPa], $r$ - radius of ring at break-up [m] and v - outward velocity of ring at break-up $[\mathrm{m} / \mathrm{s}]$.

Elek and Jaramaz noticed that the mechanical properties of real materials, such as fracture stress and strain, depend on heterogeneities (i.e., micro flaws) present in the material [13]. Therefore, modelling the fragmentation of an axissymmetric casing, which is the case of a pipe bomb, requires the imposition of some microscopic flaws which is where failures and cracking initiate. By randomizing the failure stress or strain of the material, each element will have a different failure stress or strain, thus creating weaker spots in the material. Based on this approach, known as stochastic model, Mott derived a distribution to determine the variance in failure stress or strain [24].

$$
N(m)=\frac{M_{0}}{2 \mu} \exp \left[-\left(\frac{m}{\mu}\right)^{0.5}\right] ; \mu=\frac{\bar{m}}{2} ; \bar{m}=\frac{M_{0}}{N_{0}}
$$

where is: $N(m)$ - the cumulative number of fragments or total number of fragments with the mass greater than $m, M_{0}-$ the total mass of fragments, $N_{0}$ - the total fragment number and $\bar{m}-$ the average fragment mass. The elemental premise in Mott's work is that the probability of an unfractured specimen of unit length fracturing when the strain increases from $\varepsilon$ to $\varepsilon+d \varepsilon$ has the following form:

$$
C e^{\gamma \varepsilon} d \varepsilon
$$

where parameters $C$ and $y$ represent the characteristics of material and they can be calculated by the following equations:

$$
\gamma \approx \frac{160 \sigma_{P}}{\sigma_{F}\left(1+\varepsilon_{F}\right)} ; C \approx \gamma e^{-(\varepsilon \gamma+0.5772)}
$$

where $\gamma$ - stochastic variance, $\sigma_{p}$ - strain-hardening, $\sigma_{F}-$ fracture stress, $\varepsilon_{F}-$ fracture strain and $C$ is a material parameter. According to the previous model, following Mott's distribution law, the fracture probability is determined for each element and takes the following form:

$$
p=1-\exp \left\{-\frac{C}{\gamma}[\exp (\gamma \varepsilon)-1]\right\}
$$

Even though the investigation of fragmentation patterns and velocities is not new, there is a need to study how these fragments behave in improvised explosive devices, such as pipe bombs. During the past decade, researchers have been trying to characterize IEDs from measuring the mass and velocity distributions of container fragments or microstructure deformation and hardness, as a way to correlate explosive properties with material response $[3,4,25-27]$.

To study fragmentation pattern of pipe bombs, it is necessary to carry out a series of controlled experiments to evaluate how certain parameters can affect the fragmentation effect. In 2001, Oxley et al. [25] analysed the fragments from 56 pipes bombs. The parameters assessed were: energetic fillers, initiation system, pipe material and size, device orientation, as well as, the degree of volume filled with explosives. Among all the results, two notable findings deserve highlighting. First, they found that the fragmentation behaviour could be reproducible among pipe bombs set up under the same explosive conditions and thus, it would be possible to identify the energetic filler used based on the pipe fragmentation found [25]. Secondly, as a way to quantify IEDs effects, they produced a numerical evaluator (Equation 7), called Fragment Weight Distribution Mapping (FWDM), which provides a method to assess this distribution by being relatively insensitive to the percent of recovery of fragments.

$$
\log \left(M_{x} / M_{r}\right)=m\left(m_{x} / M_{r}\right)
$$

Where $M_{x}$ - mass of a particular fragment plus all fragments heavier than it, $M_{r}$ - mass of all the recovery fragments, $m$ slope and $m_{x}-$ mass of a particular fragment.

Several studies have since been undertaken to generate additional post-blast signatures. To better evaluate fragmentation behaviour of pipe bombs, studies have been conducted focusing on mass and velocity distributions, blast overpressure, fragment thrown distance and how different temperatures may affect the results $[4,26,27]$. In these studies, the explosive filler selected was either black powder, double base smokeless powder (Alliant Bullseye, Alliant Red Dot, Alliant Herco, Alliant 2400, Alliant Reloader 22, WC 870, Winchester Action Pistol or Hodgdon Pyrodex), single-base smokeless powder (IMR-PB or IMR-4227), or a high explosive (e.g., C4, TNT or nitromethane) to be used as reference $[4,25,26]$.

Ammonium nitrate (AN) is an important ingredient in the manufacture of fertilizers and commercial explosives. The aspects that make this product so desirable in the industry are: low cost, easy access and its role as oxidant. In 2016, according to a Grand View Research report, the global ammonium nitrate market size was estimated at USD 4.67 billion [33]. For many years, AN alone was not considered an explosive. However, since the beginning of its mass production, several accidents involving AN have been reported (Oppau, 1921; Texas City, 1947; Toulouse, 2001; Texas, 2013).

Due to the large number of accidents involving $A N$ and the fact that this product has become the weapon of choice for many terrorist groups, Kirk Yeager, an FBI forensic expert, carried out tests to study the detonability of fertilizer grade ammonium nitrate (FGAN) with a booster [2]. In his report, the test results showed that FGAN prills alone (without a fuel) could be detonable and once initiated, could endure a stable detonation without requiring a high external confinement [2]. However, it should be noted that this result did not imply that any amount of AN was detonatable. A critical diameter, which is the minimum diameter of the explosive in which a steady detonation may still occur, is necessary so that the detonation of the booster can be transmitted to the product. Although this information was not given by Yeager in his report [2], Zygmunt [34] undertook some studies on detonation parameters of mixture containing ammonium nitrate and aluminium, known as ammonals and hydro-ammonals, and noticed that some additives, such as aluminium, TNT, nitro glycerine, and others, could improve the AN detonation ability by reducing the critical diameter and increasing the detonation velocity. It was concluded that the addition of $1 \%$ 
of aluminium to AN could give a critical diameter below 20 $\mathrm{mm}$, while the same value could only be seen with the addition of approximately $20 \%$ of TNT.

Overall, pipe bombs remain a significant modern threat and a weapon of choice for both domestic and international terrorism. While studies have indicated that their effectiveness is affected by parameters such as material, explosive, initiator, etc. work has yet to be undertaken to investigate the effects of pipe wall thickness.

\subsection{Aims and Objectives}

The aim of this study is to explore the influence of wall thickness on fragmentation behaviour experimentally, in order to assess the suitability of such models in the aid of forensic investigation of post blast events.

To achieve this, in-house manufactured pipe bombs were designed and tested with two different wall thickness.

\section{Materials and Methods}

This project assessed fragmentation pattern of metallic pipe bombs. For the experiments, the pipes were filled with aluminized ammonium nitrate (AAN) - mass ratio of 9:1 AN to aluminium - at a density of $1.03 \mathrm{~g} . \mathrm{cm}-3$. AAN was selected as the explosive filler as literature indicates that aluminium is a better sensitizer to AN, in comparison with TNT and nitro glycerine, and explosive properties, such as critical diameter and detonation velocity of ammonals depend on the aluminium content of those mixtures [34].

\subsection{Experimental Protocol}

Six pipe bombs were manufactured from seamless mild steel S235J tube supplied by Precision Profiles, UK. This same metal was also used for end caps (top and bottom). Pipe-bomb dimensions were $38 \mathrm{~mm}$ by $229 \mathrm{~mm}$ (3), and 34 $\mathrm{mm}$ by $229 \mathrm{~mm}$ (3). Each device had one of its caps drilled (7.5 mm hole) to allow the insertion of an electric blasting cap \#8 (1g of PETN). As shown in Fig. 2, every pipe had a constant inner diameter of $28 \mathrm{~mm}$ whilst the outer diameter was either $34 \mathrm{~mm}$ or $38 \mathrm{~mm}$ (threads excluded). The thread region in every device was filled with Styrofoam to assure that the explosive filler (110 $\mathrm{g}$ of AAN) remained only in the non-thread region. The styrofoam in the top-end cap had a groove to accommodate a $5 \mathrm{~g}$ of booster (64\% of PETN and $36 \%$ of nitrocellulose). To help differentiation among fragments within the building, all devices were painted in different colours (Fig.

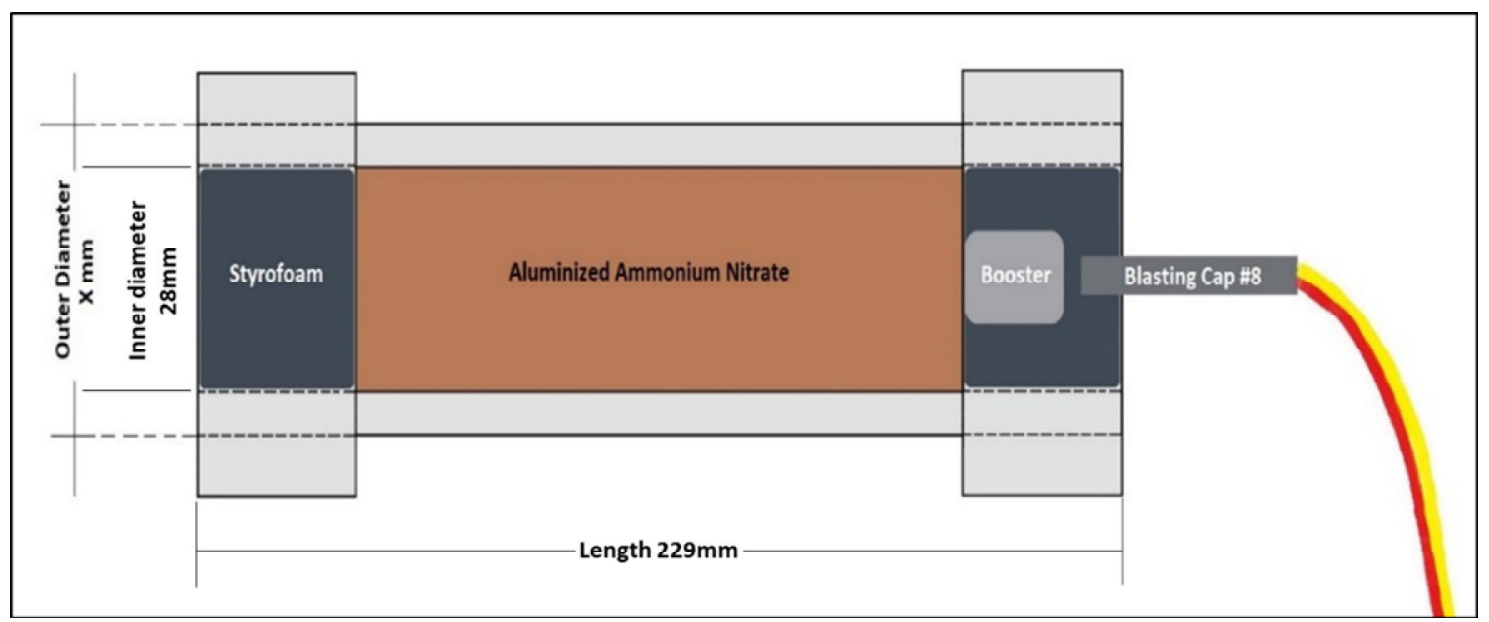

Figure 2 - Diagrammatic representation of Pipe Bomb construction for all test samples with an outer diameter of $X$ being either 34 or $38 \mathrm{~mm}$. 


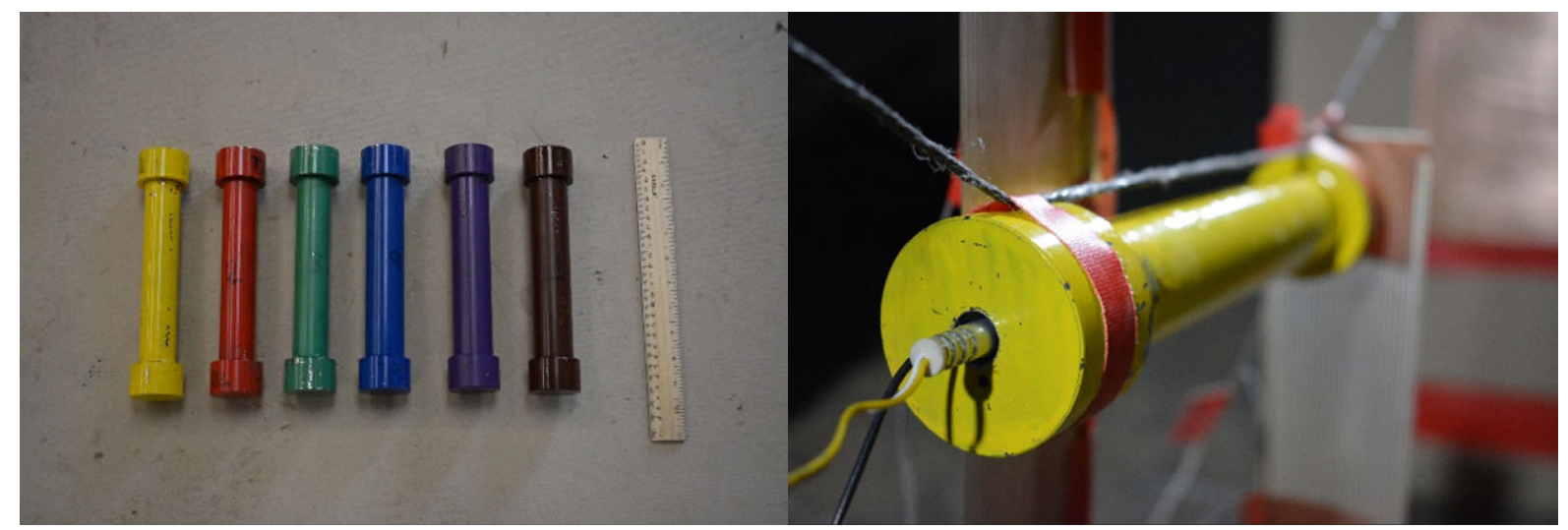

Figure 3 - Pipe bomb samples (\#1, \#2, \#3, \#4, \#5 and \#6) from left to right (left) and an illustration of pipe \#1 in the arena.

A total of six devices were fired. The experiment was carried out within the containment building at Explosives Ranges on the Explosives Research and Demonstration Area, located in the Defence Academy, in Shrivenham, UK.

Due to financial limitations, the detonation area was prepared (Fig. 4) by placing only two witness plates perpendicularly to each other to capture pipe fragments. Each witness plate was equipped with recovery packs, consisting of 20 cardboard sheets (dimensions of $1015 \mathrm{~mm}$ height $\times 760 \mathrm{~mm}$ width $\times 3.8 \mathrm{~mm}$ depth per sheet) supplied by Limehouse Board Mills, UK. Each pack was labelled and its position recorded. For each detonation a pipe bomb was placed in between the witness plates $(1000 \mathrm{~mm}$ apart) with the bottom-end cap facing the first witness plate. The pipe bomb was suspended at a height of $500 \mathrm{~mm}$ (Fig. 4) and initiated from the "top" end cap.

The fragments velocity was measured with the aid of four copper foils acting as electrical conductive surfaces: the first and second were positioned in front of the recovery packs, while the third was $10 \mathrm{~mm}$ away from the bottom-end cap and the fourth was attached to the "top" end cap. The third and the fourth positions were used to trigger the softwarecontrolled logic analyser, whereas the first and second positions were used to measure the arrival time of fragments from the pipe walls and the endcaps.

Every copper foil is an open circuit, so whenever fragments hit these foils, they close the circuit and are recorded digitally. The comparison between the arrival time of fragments and the initial time recorded by the closest foils, combined with the distance between the foils, is supposed to allow the determination of fragments velocities when they hit the panels. However, a limitation of this approach is: if by any chance, a fragment hit the circuit and remains in contact with it, the copper foil apparatus will only be able to record the speed of the fastest fragment.

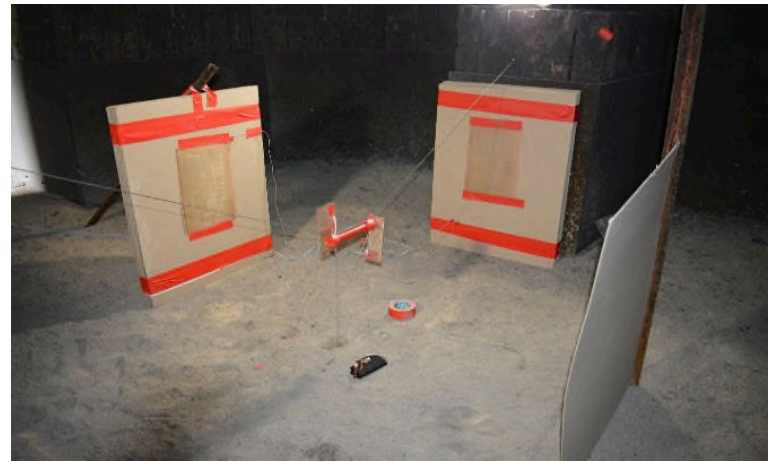

Figure 4 - Experimental set up for capturing fragments and record their velocities.

After each firing, the fragments were collected from the environment (ground, walls and ceilings) as well as extracted from recovery packs with the help of pliers and magnets. Post blast fragment masses were determined using a Mettler PE 16 analytical balance with a $0.1 \mathrm{~g}$ precision. Fragments with mass smaller than $0.1 \mathrm{~g}$ were counted, but the mass was assumed as zero.

\section{Results and Discussion}

\subsection{Experimental Results}

Fig. 7 shows the fragments profile produced by three samples with $3 \mathrm{~mm}$ of pipe wall thickness (top) and three samples with $5 \mathrm{~mm}$ of pipe wall thickness (bottom). Even though the explosive filler was the same for all devices, the differences can be noticed by fragments size, velocity and mass distribution (Fig. 7). For $38 \mathrm{~mm}$ diameter x $229 \mathrm{~mm}$ length mild steel seamless pipes, the number of fragments collected were 61,75 and 68 , whereas for $34 \mathrm{~mm}$ diameter $\mathrm{x}$ $229 \mathrm{~mm}$ length pipe bombs, the number of fragments gathered were 70,56 and 66. Every fragment was weighed individually, however, to preserve the pattern of fragmentation, pipe thread pieces that became attached to the end caps after the detonation, were kept and weighed together. For the six samples, the percent recovery ranged from 65 to $76 \%$, averaging at $72.04 \pm 4.23 \%$. Table 3 shows the pipe and fragment weight, the percent recovery and the fastest fragment velocity for each pipe bomb. 

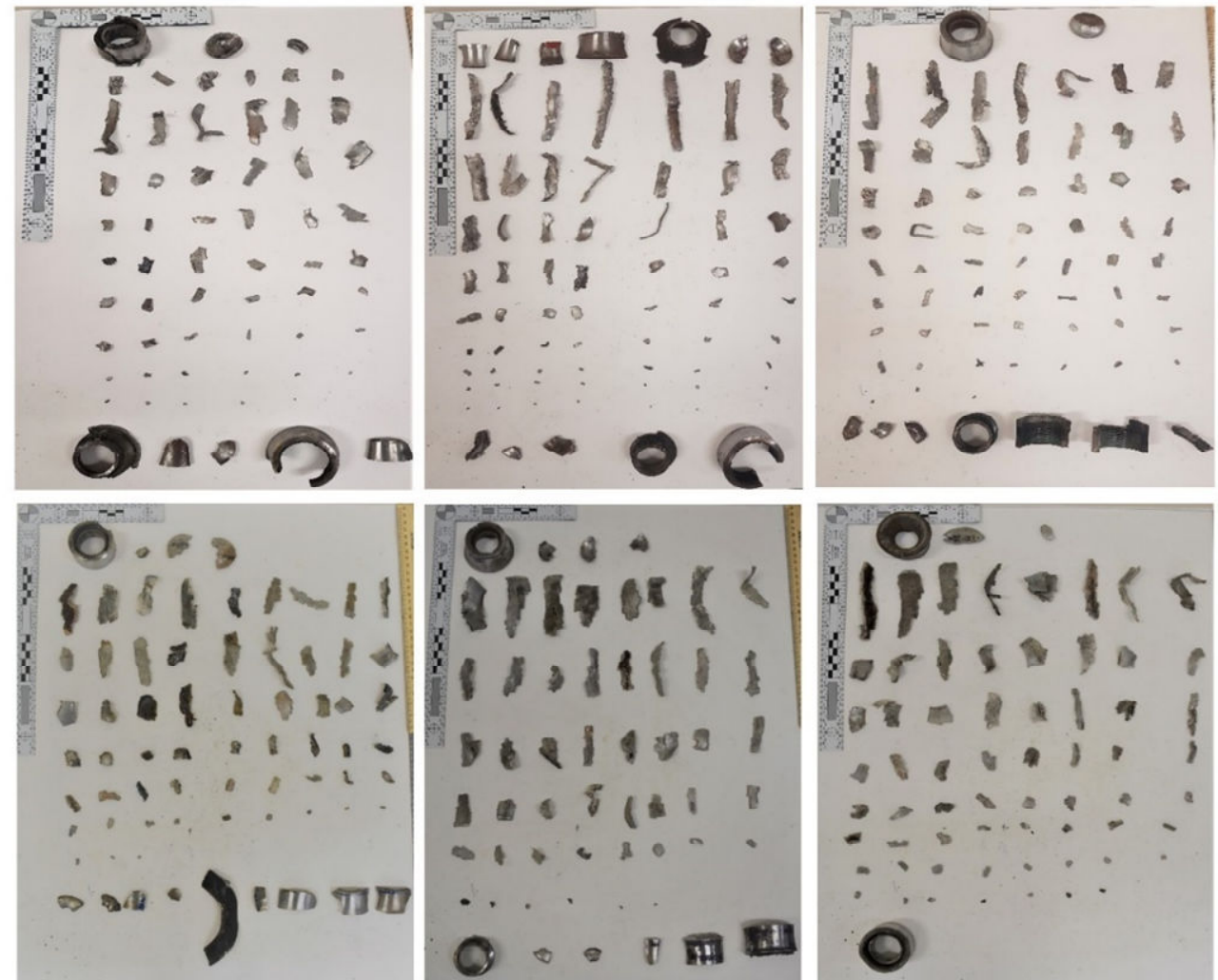

Figure 5 - Fragments of seamless steel pipes filled with Aluminized Ammonium Nitrate categorized as bottom end cap (top line), pipe body (middle) and top end cap (bottom line), where the detonation took place. Three samples (pipe \#1, \#2 and \#3) of $38 \mathrm{~mm}$ diameter $\times 229$ $\mathrm{mm}$ length (top) and three samples (pipe \#4, \#5 and \#6) of $34 \mathrm{~mm}$ diameter $\times 229 \mathrm{~mm}$ length (bottom).

An attempt was made to organize the fragments collected according to the initial pipe bomb parts: top end cap (where the devices were initiated), pipe body and bottom end cap. In five samples, it was noticed that the bottom end cap remained attached to the pipe thread. This showed that there is a certain degree of reproducibility of fragmentation among these samples due to the same explosion condition.
It was also noticed that the pipe thread attached to the top end cap of pipe \#4 failed and opened completely. It was suspected that this behaviour was due to intrinsic material defects in the metal casing.

Table 1 - Pipe bomb parameters and results from the experiments.

\begin{tabular}{|c|c|c|c|c|c|c|c|}
\hline \multirow{2}{*}{$\begin{array}{l}\text { \# } \\
\stackrel{0}{0} \\
\text { a }\end{array}$} & \multirow{2}{*}{$\begin{array}{l}\frac{N}{N} \\
\Phi \\
\frac{0}{\alpha}\end{array}$} & \multirow{2}{*}{$\begin{array}{l}\frac{ \pm}{5} \\
\frac{0}{0} \\
\vdots \\
0 \\
0 \\
\frac{0}{2}\end{array}$} & \multirow{2}{*}{ 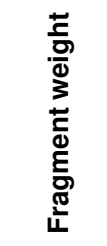 } & \multirow{2}{*}{ 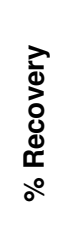 } & \multirow{2}{*}{ 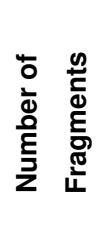 } & \multicolumn{2}{|c|}{ Fastest Fragment Velocity } \\
\hline & & & & & & $\stackrel{\Xi}{\frac{0}{2}}$ & $\begin{array}{l}\frac{0}{0} \\
0 \\
\text { రิ } \\
\end{array}$ \\
\hline 1 & \multirow{3}{*}{ 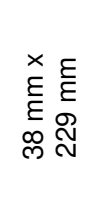 } & $1093.1 \mathrm{~g}$ & $755.2 \mathrm{~g}$ & $69 \%$ & 61 & $N / D^{*}$ & $N / D^{*}$ \\
\hline 2 & & $1087.8 \mathrm{~g}$ & $831.5 \mathrm{~g}$ & $76 \%$ & 75 & $967 \mathrm{~m} / \mathrm{s}$ & $517 \mathrm{~m} / \mathrm{s}$ \\
\hline 3 & & $1084.3 \mathrm{~g}$ & $824.8 \mathrm{~g}$ & $76 \%$ & 68 & $\mathrm{~N} / \mathrm{D}^{*}$ & $N / D^{*}$ \\
\hline 4 & 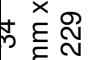 & $1392.2 \mathrm{~g}$ & $899.8 \mathrm{~g}$ & $65 \%$ & 70 & $854 \mathrm{~m} / \mathrm{s}$ & $605 \mathrm{~m} / \mathrm{s}$ \\
\hline
\end{tabular}




\begin{tabular}{|c|c|c|c|c|c|c|}
\hline 5 & $1391.6 \mathrm{~g}$ & $1040.3 \mathrm{~g}$ & $75 \%$ & 56 & $805 \mathrm{~m} / \mathrm{s}$ & $630 \mathrm{~m} / \mathrm{s}$ \\
\hline 6 & $1393.1 \mathrm{~g}$ & $992.5 \mathrm{~g}$ & $71 \%$ & 66 & $807 \mathrm{~m} / \mathrm{s}$ & $614 \mathrm{~m} / \mathrm{s}$ \\
\cline { 3 - 7 } & & &
\end{tabular}

As expected, thick pipes produced fragments with bigger sizes, thus heavier, than the thin ones. Hence, as displayed by Figs. 8 and 9 , histograms with cumulative relative frequencies distribution were used to represent fragments weight distribution and to allow comparison between the thin and the thick pipes.

For the thin pipes, the pipe wall fragments ranged from 0 to $15 \mathrm{~g}$, while the end-cap fragments ranged from 5 to $300 \mathrm{~g}$. For the thick devices, the pipe wall fragments ranged from 0 to $35 \mathrm{~g}$, while the end-cap fragments ranged from $5 \mathrm{~g}$ to 300 $g$. The cumulative relative frequency distribution for the three thin pipes showed that $89 \%$ of the number of fragments have their masses ranging from 0 to $15 \mathrm{~g}$; whereas for the thick devices, the same $89 \%$ of the number of fragments was achieved with masses ranging from 0 to $20 \mathrm{~g}$. Therefore, we may assume that thickness may affect the fragmentation behaviour. It should be noted that this result is in agreement with Mott's equation for fragment size, under the assumptions of using the same casing gives the same mechanical properties, thus only the radius and the velocities at break-up are varying. Based on this, thin walls give smaller fragments, while thick walls give larger ones [19].

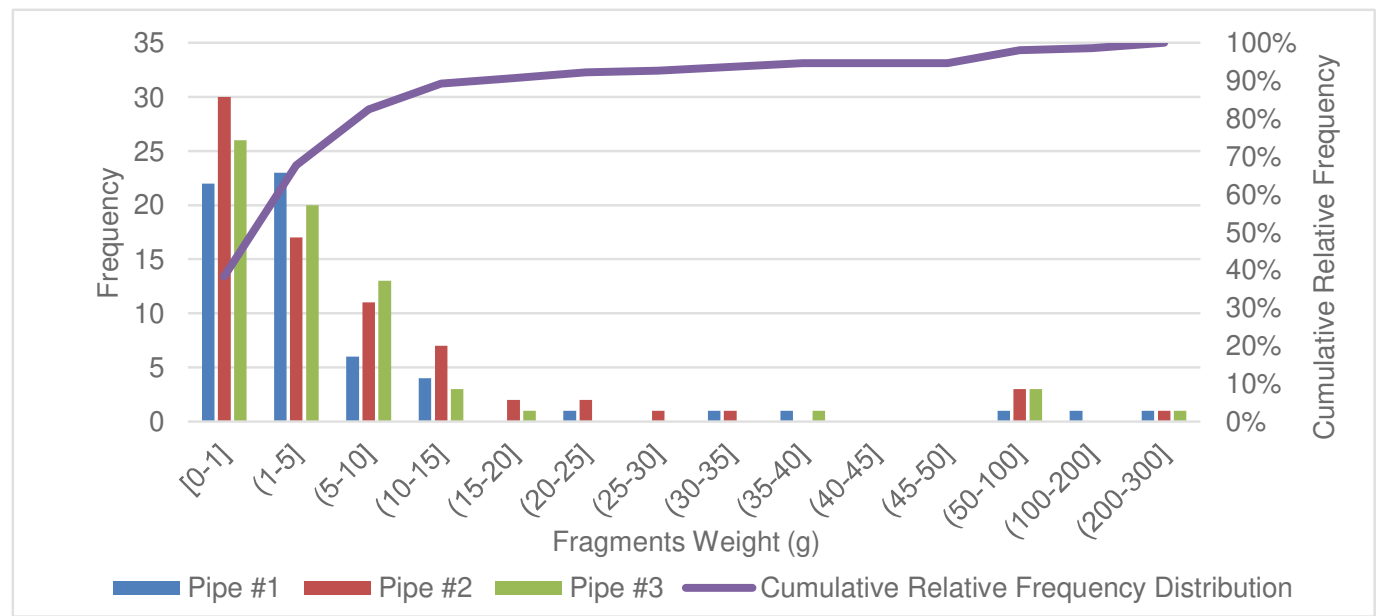

Figure 6 - Histogram of fragment weight distribution of mild steel devices filled with AAN with $3 \mathrm{~mm}$ of pipe wall thickness.

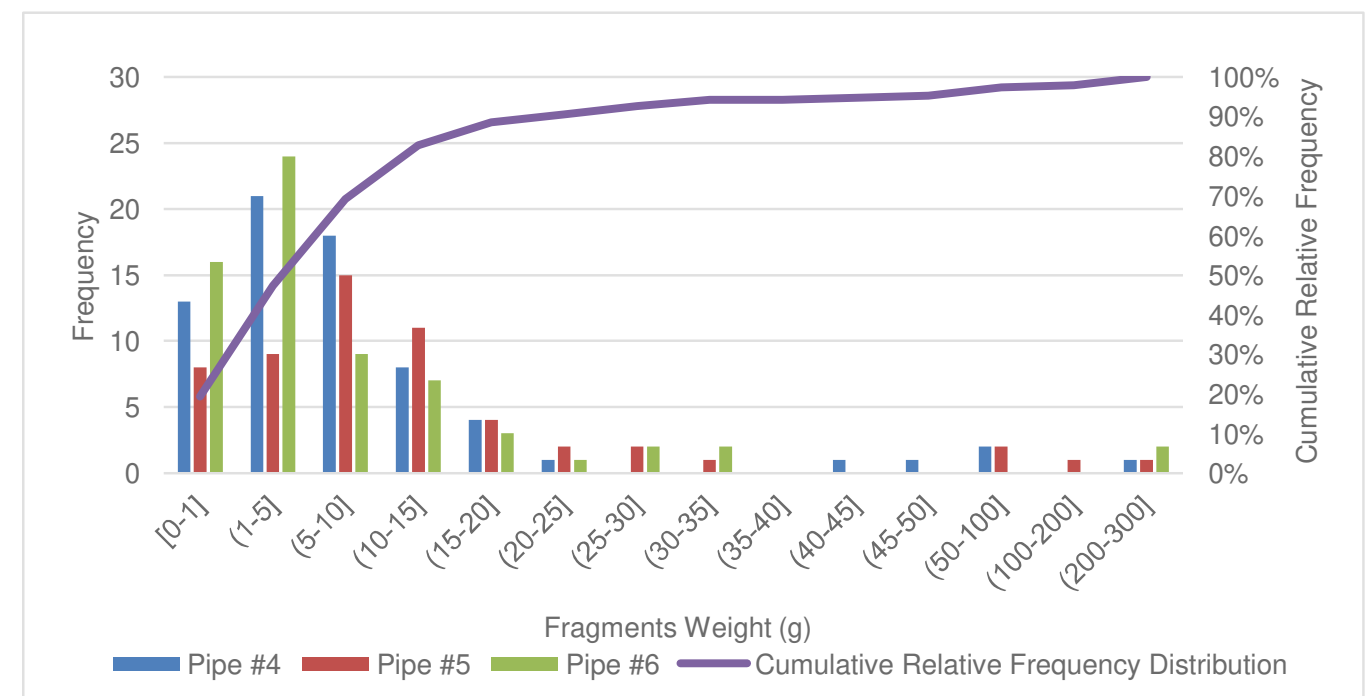
$\begin{aligned} & \text { Figure } 7 \text { - Histogram of fragment weight distribution of mild steel devices filled with AAN with } 5 \text { mm of } \\ & \text { pipe }\end{aligned}$ wall
thickness.

From Table 3, we can observe that the velocities of the pipe wall fragments are higher than the end-cap fragments.
This happened because, after pipe bombs (initiated on-axis) had overcome the metal case strength, their fragments dispersed uniformly around the axis and since threaded parts 
of the end caps were heavier and thicker than pipe walls, they travelled slower. Moreover, the velocity data for pipe \#2 showed that pipe wall fragments from thin pipes travelled at higher speeds relative to the fragments generated by the thick pipes, while the opposite behaviour was observed for end-cap fragments. As discussed, the copper foil apparatus only measured the speed of the fastest fragment. After the first fragment hit the copper foil, the circuit was closed and it didn't record any more hit. Due to human error prediction, for pipe \#1 and \#3, the time-base for the data capture was set to be faster than the actual phenomena, therefore the software stopped recording before the fragments had arrived at the witness plates and their velocities were not registered.

As a way to explain the fragment velocities behaviour, the Gurney model for cylindrical bombs was discussed [23]. In this study, the explosive and its mass were kept the same for all devices, thus the only parameter changing was the casing mass. From this equation, we may assume heavier casings lead to lower fragment velocities. Therefore, due to the fact that thick pipes are heavier, the pipe wall fragments velocities will be lower.

An attempt was made to verify if the Gurney equation would be applicable to the experiments. By looking at the original Gurney equation (equation 1), it would be reasonable to assume that the initial velocities are independent of the geometry size. However, Weinland [40] observed that real experiments were affected by it. In his work, he studied the effect of scaling by assessing the ratio of length over diameter (L/D) for cylinders and he found out that if $L / D \geq 6$, the Gurney constant is not affected by scaling. Since the outer diameter of the pipe bombs used in this project were either 34 or $38 \mathrm{~mm}$, the ratio L/D was equal or above 6 , thus it was assumed that the Gurney constant shouldn't be affected by anything other than the casing mass. The values found were compared to the Gurney constant obtained from the literature for AAN mixtures with $10 \%$ of aluminium [41].

Table 2 - Calculated Gurney constants.

\begin{tabular}{|c|c|c|c|c|c|}
\hline Pipe \# & Casing Mass (M) & Explosive Mass (C) & Fragment Velocity & Gurney Constant $(\sqrt{2 E})$ & Gurney Constant [41] \\
\hline 1 & $604.0 \mathrm{~g}$ & $110 \mathrm{~g}$ & $\mathrm{~N} / \mathrm{D}^{*}$ & - & \multirow{6}{*}{$1.78-1.98 \mathrm{~km} / \mathrm{s}$} \\
\hline 2 & $598.8 \mathrm{~g}$ & $110 \mathrm{~g}$ & $967 \mathrm{~m} / \mathrm{s}$ & $2.36 \mathrm{~km} / \mathrm{s}$ & \\
\hline 3 & $595.4 \mathrm{~g}$ & $110 \mathrm{~g}$ & $\mathrm{~N} / \mathrm{D}^{*}$ & - & \\
\hline 4 & $903.3 \mathrm{~g}$ & $110 \mathrm{~g}$ & $854 \mathrm{~m} / \mathrm{s}$ & $2.52 \mathrm{~km} / \mathrm{s}$ & \\
\hline 5 & $902.4 \mathrm{~g}$ & $110 \mathrm{~g}$ & $805 \mathrm{~m} / \mathrm{s}$ & $2.37 \mathrm{~km} / \mathrm{s}$ & \\
\hline 6 & $903.8 \mathrm{~g}$ & $110 \mathrm{~g}$ & $807 \mathrm{~m} / \mathrm{s}$ & $2.38 \mathrm{~km} / \mathrm{s}$ & \\
\hline
\end{tabular}

Using the fragment velocities displayed at Table 3, Gurney velocities were calculated and shown in Table 4. Since Gurney

model was developed for open cylinders, only the pipe weight was used for calculating the ratio $\mathrm{M} / \mathrm{C}$. Out of four pipes, three (pipes \#2, \#5 and \#6) were proven to best fit the model, showing calculated values ranging from 2.36 to $2.38 \mathrm{~km} / \mathrm{s}$. Thus, we may assume that, under the experimental conditions set up in this project, the Gurney model could predict fragment velocities. However, also note that all the values calculated were higher than the published range of 1.78 and $1.98 \mathrm{~km} / \mathrm{s}$. It was assumed that this happened because this study used an AAN with a higher density (1.03 g.cm-3) than the density reported $(0.953 \mathrm{~g} . \mathrm{cm}-3)$ by the literature, which increased the velocity of detonation, thus making the conversion of mechanical energy from the detonation into fragment velocities more efficient.

Gurney approach for cylindrical bombs didn't include end caps, thus it could not explain the end-cap fragments behaviour. However, considering that thick pipes take longer time to expand than thin pipes, a more intense build-up of pressure inside the pipe is expected to happen before fracture. With high pressures acting on the inner area of the cylinder, there will be a higher initial acceleration, which gives higher initial velocities to the end-cap fragments. Besides, since part of the kinetic energy was lost in pulling the pipe apart, thicker pipes posed more resistance to fragmentation, resulting in lower pipe wall velocities.

\section{Conclusion}

Overall, the experiments showed that the thicker the pipe, the larger the fragments produced and that the fragments velocities obtained from the detonations followed the Gurney model for initial fragment velocities. The impact of endcaps on the pipe bomb and resultant variation in fragment velocity, and the potential for $\mathrm{Al}$ to cause higher velocities were interesting findings that require more experimentation to explain.

\section{Further Work}

Regarding the experiments, due to financial limitations, it was not possible to set up the experiment with a $360^{\circ}$ approach and many fragments were lost within the containment building. Hence, this approach could not only increase the percentage of recovery but also be an alternative way of measuring fragment velocities by assessing the penetration on the recovery packs. Since pipe bombs are very common due to materials being readily available, we recommend that further studies using regularly available metal tubes be conducted. Moreover, a metallography study should be done pre and post experiment to evaluate the effects of flaws in the metal casing. 
[1] B. Mohanty, Forensic Investigation of Explosions, 2nd ed., CRC Press, 1998. doi:10.1017/CBO9781107415324.004.

[2] J.T. Thurman, Practical Bomb Scene Investigation, 3rd ed., CRC Press, 2017.

[3] O. Gregory, J. Oxley, J. Smith, M. Platek, H. Ghonem, E. Bernier, M. Downey, C. Cumminskey, Microstructural characterization of pipe bomb fragments, Mater. Charact. 61 (2010) 347-354 doi:10.1016/j.matchar.2009.12.017.

[4] D. Bors, J. Cummins, J. Goodpaster, The Anatomy of a Pipe Bomb Explosion: Measuring the Mass and Velocity Distributions of Container Fragments, J. Forensic Sci. 59 (2014) 42-51. doi:10.1111/15564029.12294.

[5] A.J. Gibbons, J.N. Farrier, S.J. Key, The pipe bomb: a modern terrorist weapon., J. R. Army Med. Corps. 149 (2003) 23-26. doi:10.1136/jramc-149-01-04.

[6] J.M. Dewey, Experimental Methods of Shock Wave Research, in: Exp. Methods Shock Wave Res. Springer, Cham, 2016: pp. 53-86. doi:10.1007/9783-319-23745-9.

[7] S. Lichorobiec, V. Kavicky, L. Figuli, Comprehensive Assessment of Potential,Threats to All Kinds of Events Arising from the Explosion of Pipe Bomb, Key Eng. Mater. 755 (2017) 219-228. doi:10.4028/www.scientific.net/KEM.755.219.

[8] Global Terrorism Database, GTD Search Results for terrorist incidents in the US, 1970-2016, Natl. Consort. Study Terror. Response to Terror. (2017).

[9] United States Bomb Data Center, United States bomb data center (USBDC) Explosives Incident report (EIR) 2015, (2015). https://www.atf.gov/rulesand-

regulations/docs/report/2015usbdcexplosiveincidentr eportpdf/download.

[10] United States Bomb Data Center, United States bomb data center (USBDC) Explosives Incident report (EIR) 2014, (2014). https://www.atf.gov/explosives/docs/report/2014usbdc-explosive-incident-report/download.

[11] United States Bomb Data Center, United States bomb data center (USBDC) Explosives Incident report (EIR) 2016, (2016). https://www.atf.gov/explosives/docs/report/2016explosives-incident-report/download.

[12] United States Bomb Data Center, United States bomb data center (USBDC) Explosives Incident report (EIR) 2017, (2017). https://www.atf.gov/resourcecenter/docs/report/2017-explosives-incident-reporteir/download.

[13] P. Elek, S. Jaramaz, Modeling of Fragmentation of Rapidly Expanding Cylinders, Theor. Appl. Mech. 32 (2005)

$113-130$ http://www.doiserbia.nb.rs/Article.aspx?ID=145055840502113E\%5Cnpapers3://publication/doi/10.22 98/TAM0502113E

[14] G.Y. Huang, W. Li, S.S. Feng, Axial distribution of Fragment Velocities from cylindrical casing under explosive loading, Int. J. Impact Eng. 76 (2015) 2027. doi:10.1016/j.ijimpeng.2014.08.007.

[15] M. Ugrčić, M. Ivanišević, Characterization of the Natural Fragmentation of Explosive Ordnance Using the Numerical Techniques Based on the FEM, Sci. Tech. Rev. 65 (2015) 14-27. doi:10.5937/STR1504016U.

[16] M. Ugrčić, Numerical Simulation of the Fragmentation Process of High Explosive Projectiles, Sci. Tech. Rev. 63 (2013) 47-57. http://www.vti.mod.gov.rs/ntp/rad2013/2-13/3/3.pdf.
I.G. Cullis, P. Dunsmore, A. Harrison, I. Lewtas, R. Townsley, Numerical simulation of the natural fragmentation of explosively loaded thick walled cylinders, Def. Technol. 10 (2014) 198-210. doi:10.1016/j.dt.2014.06.003.

[18] H. Grisaro, A.N. Dancygier, Numerical study of velocity distribution of fragments caused by explosion of a cylindrical cased charge, Int. J. Impact Eng. $86 \quad$ (2015) 1-12. doi:10.1016/j.ijimpeng.2015.06.024.

[19] N.F. Mott, Fragmentation of shell cases, Proc. R. Soc. A Math. Phys. Eng. Sci. 189 (1947) 300-308. doi:10.1098/rspa.1947.0042.

[20] A. Rotariu, E. Trana, Modelling and simulation for ballistic protection, in: Proc. Greener Safer Energ. Ballist. Syst. Conf., Bucharest, Romania, 2016: p. 27.

[21] E. Trană, A. Rotariu, F. Bucur, Numerical Simulation Study on the Ring, MTA Rev. 2 (2015) 179-188.

[22] H.A. Richard, M. Sander, Fatigue Crack Growth: Detect-Assess-Avoid, 2016

[23] R. W. Gurney, The Initial Velocities of Fragments from Bombs, Shell, Grenades, Aberdeen, Maryland, 1943

[24] N.F. Mott, E.H. Linfoot, D. Grady, A Theory of Fragmentation, in: Fragm. Rings Shells - Leg. N.F. Mott, 1st ed., Springer-Verlag Berlin Heidelberg, 2006: pp. 207-225. doi:10.1007/978-3-540-271451_9.

[25] J.C. Oxley, D. Ph, J.L. Smith, E. Resende, E. Rogers, R.O. Jc, S. JI, E. Resende, E. Rogers, Improvised Explosive Devices: Pipe Bombs *, J. Forensic Sci. 46 (2001) 510-534. doi:10.1520/JFS15000J.

[26] J.C. Oxley, J.L. Smith, E.T. Bernier, F. Sandstrom, G.G. Weiss, G.W. Recht, D. Schatzer, Characterizing the Performance of Pipe Bombs, J. Forensic Sci. 63 (2018) 86-101. doi:10.1111/15564029.13524.

[27] D. Bors, J. Cummins, J. Goodpaster, The anatomy of a pipe bomb explosion: The effect of explosive filler, container material and ambient temperature on device fragmentation, Forensic Sci. Int. 234 (2014) 95-102. doi:10.1016/j.forsciint.2013.10.017.

[28] A. Gullerud, J. Hollenshead, Coupled EulerLagrange simulations of metal fragmentation in pipe bomb configurations, Procedia Eng. 204 (2017) 202-207. doi:10.1016/j.proeng.2017.09.774.

[29] X. Quan, B. Gerber, M. Cowler, N. Birnbaum, Simulation of Blast and Fragment Loading Using a Coupled Multi-Solver Approach, Trans. Tianjin Univ. 12 (2006) 182-187.

[30] G.E. Fairlie, The Numerical Simulation of High Explosives using AUTODYN-2D \& 3D, Inst. Explos. Eng. 4th Biannu. Symp. (1998) 13.

[31] Y. Li, Y. hua Li, Y. quan Wen, Radial distribution of fragment velocity of asymmetrically initiated warhead, Int. J. Impact Eng. 99 (2017) 39-47. doi:10.1016/j.ijimpeng.2016.09.007.

[32] W. Arnold, E. Rottenkolber, Fragment mass distribution of metal cased explosive charges, Int. J. Impact Eng. 35 (2008) 1393-1398. doi:10.1016/j.jijmpeng.2008.07.049.

[33] Grand View Research, Ammonium Nitrate Market Analysis And Segment Forecasts To 2025, USA, 2017. https://www.grandviewresearch.com/industryanalysis/ammonium-nitrate-market.

[34] B. Zygmunt, Detonation parameters of mixtures containing ammonium nitrate and aluminium, Cent. Eur. J. Energ. Mater. 6 (2009) 57-66.

[35] ANSYS Inc., ANSYS AUTODYN User's Manual, 15317 (2013) 1-502.

[36] B. M Dobratz, P. C Crawford, LLNL Explosives 
Handbook Properties of Chemical Explosives and Explosive Simulants, 1985.

[37] P. Sherkar, A.S. Whittaker, A.J. Aref, Modeling the Effects of Detonations of High Explosives to Inform Blast-Resistant Design, MCEER Tech. Reports. 10 (2010) 188. doi:10.13140/RG.2.1.3978.4565.

[38] M.-H. Yu, J.-C. Li, 3D Simulation of Normal and Oblique Penetration and Perforation, in: Comput. Plast. With Emphas. Appl. Unified Strength Theory, Springer Berlin Heidelberg, Berlin, Heidelberg, 2012 pp. 321-331. doi:10.1007/978-3-642-24590-9 13.

[39] G.R. Johnson, W.H. Cook, Fracture characteristics of three metals subjected to various strains, strain rates, temperatures and pressures, Eng. Fract. Mech. 21 (1985) 31-48. doi:10.1016/00137944(85)90052-9.

[40] C.E. Weinland, A Scaling Law for Fragmenting Cylindrical Warheads, (1969).

[41] D.L. Robbins, E.K. Anderson, M.U. Anderson, S.I. Jackson, Cylinder Test Characterization of an Ammonium Nitrate and Aluminum Powder Explosive, 15th Int. Symp. Detonation. (2014). http://public.lanl.gov/sjackson/papers/2015-

AndersonAmmonal.pdf.

[42] E. Galuta, W. Regig, Numerical Simulations of RC Panels Subjected to High Speed Projectile - Erosion Selection in AUTODYN-3D code, 4 (2017) 25-30. http://ijiset.com/vol4/v4s8/IJISET_V4_108_03.pdf.

[43] J.M. McGlaun, S.L. Thompson, M.G. Elrick, CTH: A three-dimensional shock wave physics code, Int. J. Impact Eng. 10 (1990) 351-360. doi:10.1016/0734743X(90)90071-3.

[44] V.M. Gold, Fragmentation model for large L/D (Length over Diameter) explosive fragmentation warheads, Def. Technol. 13 (2017) 300-309. doi:10.1016/j.dt.2017.05.007. 


\section{Appendix}

Pipe bomb design

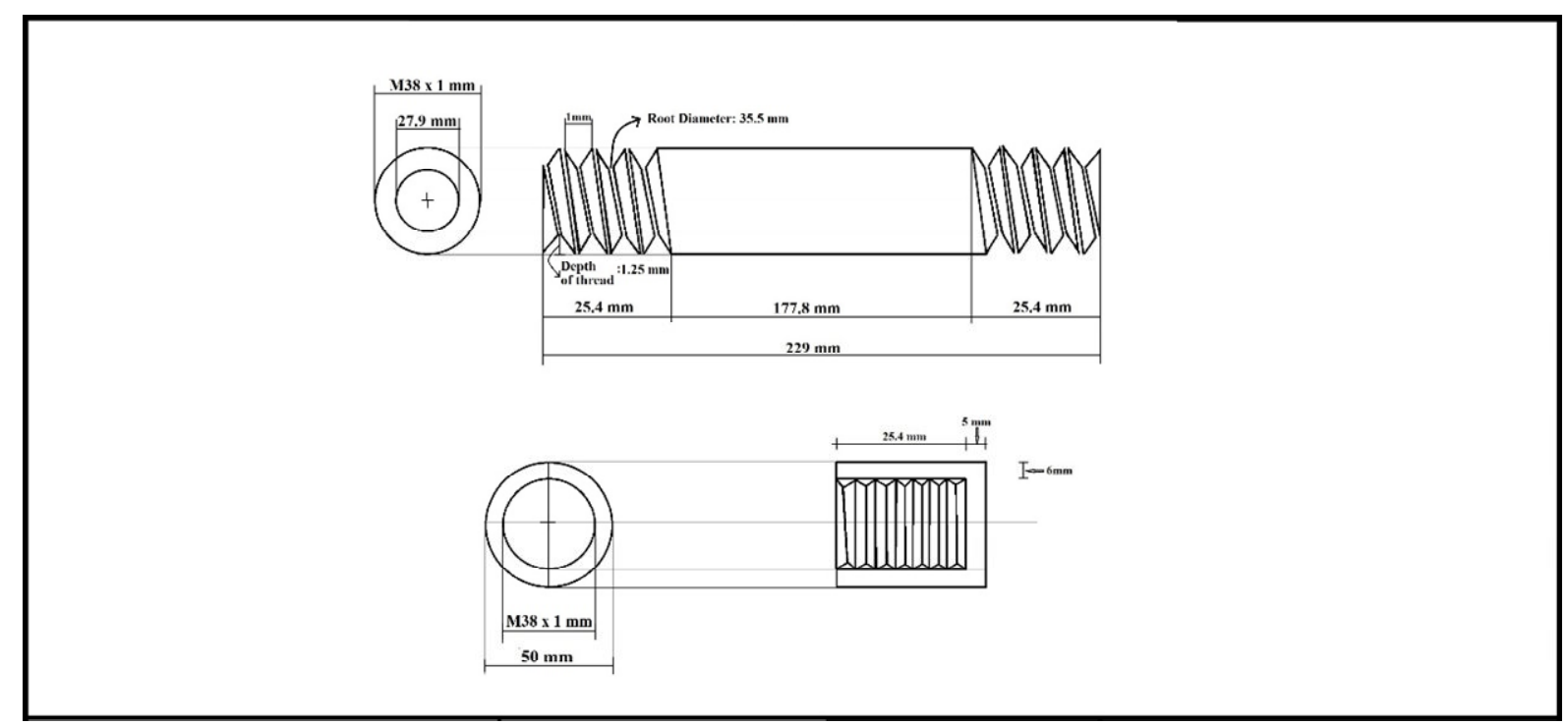

Figure A-1 - Pipe and thread design. 